\title{
Perfil epidemiológico de puérperas e prevalência de anticorpos para infecção pelo HIV e vírus da hepatite $C$ em Cuiabá, Mato Grosso
}

\author{
Epidemiologic profile of puerperals and prevalence of antibodies \\ for HIV and hepatitis $\mathrm{C}$ virus infection \\ in Cuiabá, Mato Grosso
}

\author{
Maria Angélica de Macedo Orione ${ }^{1}$, Sandra Breder Assis² e Francisco José Dutra Souto ${ }^{3}$
}

\begin{abstract}
RESUMO
Foi realizado inquérito soroepidemiológico com o objetivo de conhecer a prevalência da infecção pelo vírus da imunodeficiência humana, de anticorpos contra o vírus da hepatite $C$ (anti-HCV), fatores de risco associados à transmissão parenteral e o perfil epidemiológico de puérperas atendidas em três hospitais conveniados com o Sistema Único de Saúde em Cuiabá-MT, no período de dezembro de 2001 a maio de 2002. Mil seiscentas e sete mulheres foram estudadas e entrevistadas de modo a se obter informações sócio-demográficas e epidemiológicas que poderiam estar associadas à transmissão do vírus da imunodeficiência humana. Foram pesquisados anticopos anti-HIV e anti-HCV, através do teste ELISA. A prevalência de infecção pelo vírus da imunodeficiência humana foi de 0,5\% (IC95\%=0,2 a 1,0). A maioria das participantes tinha apenas nível de ensino fundamental (58,4\%) e mantinha relacionamento estável com parceiro fixo (73\%). Não foi evidenciada associação entre a presença de anti-HIV e o nível sócioeconômico, escolaridade, fatores de risco para doenças de transmissão sanguínea ou sexual, e com a presença de comportamento sexual de risco nas entrevistadas e em seus parceiros (relacionamentos com múltiplas parceiras ou bissexualidade). Presumiu-se que a via de transmissão heterossexual foi a principal causa de infecção nas mulheres em idade fértil na região. A prevalência do antiHCV foi de 0,4\% (IC95\%= 0,1;0,8), sendo mais freqüente entre as participantes mais velhas.
\end{abstract}

Palavras-chaves: Síndrome da imunodeficiência adquirida. Vírus da imunodeficiência humana. Hepatite C. Epidemiologia. Puérperas.

\begin{abstract}
A seroepidemiologic survey was performed aimed at estimating the prevalence of human immunodeficiency virus human immunodeficiency virus, the prevalence of hepatitis $C$ virus antibodies (anti-HCV), the risk factors associated with human immunodeficiency virus transmission and the epidemiological profile of the women in puerperal period in three public Hospitals of Cuiabá City between December 2001 and March 2002. The sample was composed of 1,607 women who were interviewed in order to obtain information about socio-demographic aspects and risk behavior. Blood samples were drawn to detect HIV and HCV antibodies using the ELISA test. The prevalence of HIV infection in this population was 0.5\% (IC95\%=0.2; 1.0). Most women had only basic level schooling (58.4\%), and they presently held a relationship with a fix partner (73\%). There were no statistically significant associations between HIV antibody and socioeconomic level, other procedures that involved the risk of HIV parenteral transmission, between antiHIV positivity and the presence of sexual behavior of risk (relationships with multiple partners or bisexuality) by the women and their partners. Currently, it is presumed that heterosexual transmission is the main cause of infection among women in reproductive age in the study area. The anti-HCV prevalence was $0.4 \%(C I 95 \%=0.1 ; 0.8)$. Anti-HCV was more common among older women.
\end{abstract}

Key-words: Acquired immunodeficiency syndrome. Human immunodeficiency virus. C Hepatitis. Epidemiology. Puerperals.

\footnotetext{
1. Departamento de Pediatria da Universidade de Cuiabá, Cuiabá, MT. 2. Departamento de Pediatria da Universidade Federal de Mato Grosso, Cuiabá, MT.

3. Departamento de Clínica Médica da Universidade Federal de Mato Grosso, Cuiabá, MT.

Endereço para correspondência: Dra. Maria Angélica de M. Orione. Av. Filinto Muller 1050/1106, Bairro Quilombo, $78045-310$ Cuiabá, MT.

Tel: 5565 3622-0154, $55653051-3567$

e-mail: ang.alv@terra.com.br

Recebido para publicação em 28/3/2005

Aceito em 26/1/2006
} 
No Brasil, como no mundo, o número de casos de aids entre mulheres aumentou drasticamente na década passada. Segundo dados do Ministério da Saúde, estima-se que no Brasil ocorram três milhões de partos por ano e que a prevalência de gestantes soropositivas encontra-se ao redor de $0,4 \%{ }^{13}$.

0 crescimento da epidemia entre as mulheres levou, conseqüentemente, ao aumento do número de casos em crianças. A transmissão materno-fetal é responsável por $90 \%$ destes casos e tem sido uma grande preocupação mundial 5 . Hoje é possível prevenir a transmissão vertical através da oferta de medicamentos para a gestante a partir da $14^{\mathrm{a}}$ semana até o parto e para o recém-nascido por seis semanas após o parto, reduzindo a transmissão em valores até $70 \%$.

Tendo em vista o longo período de latência assintomático até 0 desenvolvimento da doença, a análise da distribuição dos casos de aids apresenta retardo de aproximadamente quatro a dez anos. Para obter uma análise epidemiológica mais acurada é necessário contar com estudos transversais de prevalência, os quais permitem investigar como a infecção pelo HIV se comporta em determinados grupos populacionais em um determinado momento. Para esta infecção os estudos sentinela em gestantes são particularmente úteis, pois nos permitem extrapolar os dados encontrados à população sexualmente ativa ${ }^{7}$.

Por outro lado, o vírus da hepatite $\mathrm{C}$ (VHC) é um agente infeccioso transmitido principalmente por sangue. Diferente do HIV, seu potencial infeccioso por via sexual não é alto ${ }^{10}$. A transmissão vertical também é considerada pouco comum. Porém, pode ganhar importância epidemiológica se a prevalência entre as mulheres em idade reprodutiva for alta ou na presença de co-infecção com o HIV ${ }^{15}$.

Este inquérito foi idealizado com o intuito de estimar a prevalência da infecção pelo vírus da imunodeficiência humana (HIV) e de anticorpos contra o HCV (anti-HCV) entre puérperas das três principais maternidades públicas de hospitais conveniados com o Sistema Único de Saúde de Cuiabá, bem como identificar o perfil sócio-econômico e comportamental das gestantes da região e identificar possíveis marcadores de risco para a infecção pelo HIV.

\section{MATERIAL E MÉTODOS}

Foram incluídas no estudo mulheres puérperas internadas em três maternidades de hospitais conveniados com o SUS de Cuiabá: Hospital Geral Universitário, Hospital Santa Helena e Hospital Universitário Júlio Muller.

Para cálculo do tamanho da amostra, utilizou-se a fórmula de Kish \& Leslie (Epi Info 6.04, CDC, Atlanta, EUA). Os parâmetros utilizados foram: 1) tamanho da população de 5.000, considerando o número de partos previstos para 0 período de seis meses com base na média de nascimentos nos últimos meses nos hospitais envolvidos; 2) prevalência estimada de $0,5 \%$, baseando-se na média nacional; 3) precisão de $0,3 \%$ para mais ou para menos em torno da prevalência estimada; e 4) nível de confiança de 95\%. 0 tamanho da amostra resultante deste cálculo foi de 1.490 .
Foram incluídas no estudo as mulheres que se encontravam internadas nas maternidades citadas, nas primeiras 24 horas após o parto que concordaram em participar do estudo, no período de dezembro de 2001 a maio de 2002. Estas mulheres não foram submetidas a qualquer seleção prévia. Eram informadas sobre 0 objetivo da pesquisa e, após seu consentimento por escrito, respondiam a questionário padronizado, sendo então coletada uma amostra de sangue para estudo.

Para a elaboração do questionário utilizou-se como base questionários aplicados em bancos de sangue para a detecção de doadores de risco e questionário aplicado em outros estudos de prevalência de infecções, com adaptações aos objetivos da pesquisa do HIV ${ }^{316}$.

o questionário levantou dados pertinentes para 0 delineamento do perfil epidemiológico da puérpera portadora do HIV na população de estudo, como estado civil, escolaridade, profissão, número de bens de consumo possuídos pela entrevistada em sua casa, transfusão de hemoderivados, cirurgias anteriores, uso de drogas injetáveis e compartilhamento de seringas, história de doenças sexualmente transmissíveis e comportamento sexual de risco da mulher ou dos seus parceiros.

Através de veno-punção periférica foram coletados $5 \mathrm{ml}$ de sangue para a realização do teste ELISA para detecção de anticorpos anti-HIV-1 (incluindo o subtipo 0) e HIV-2 utilizando-se de tecnologia de ELISA de terceira geração (COBAS CORE Anti HIV1+2+0, Roche Diagnostics Corporation, Indianápolis, USA).

O projeto foi submetido e aprovado pelo Comitê de Ética em Pesquisa em Seres Humanos do Hospital Universitário Júlio Muller e pela direção clínica das três instituições.

Os soros considerados positivos pelo método ELISA foram submetidos a um novo teste pelo método de imunofluorescência indireta (IFI) no Laboratório Central do Estado de Mato Grosso - LACEN. Este exame confirmatório foi realizado na mesma amostra inicial. Os soros foram também testados para presença de anticorpos contra o HCV (anti-HCV) pelo método ELISA (COBAS CORE HCV, Roche Diagnostics Corporation. As mulheres com teste positivo foram convocadas para avaliação e seguimento no ambulatório de atendimento a pacientes soropositivos do Hospital Júlio Müller. A definição de caso foi aplicada à paciente cujo soro apresentasse resultado positivo para anti-HIV pelo método ELISA, confirmado pelo método de Imunofluorescência Indireta. Quanto ao anti-HCV, não foi realizado teste confirmatório. Consequientemente, os resultados se referem a positividade para esse teste e não para infecção confirmada.

0 gerenciamento dos dados obtidos foi feito utilizando-se 0 programa Epi Info 6.04 (Center for Diseases Control, Atlanta, EUA). Os dados foram descritos em percentuais. Variáveis contínuas e categóricas dos grupos de soropositivas e soronegativas foram comparadas, utilizando-se respectivamente o teste de Student, o teste do qui-quadrado ou o teste exato de Fisher. Foram consideradas estatisticamente significantes as análises em que a probabilidade de aceitar a hipótese nula fosse inferior a $0,05 \%$. 


\section{RESULTADOS}

Foram incluídas 1.607 mulheres no estudo, internadas em três maternidades conveniadas ao Sistema Único de Saúde (Tabela 1). A idade das mulheres estudadas variou de 13 a 50 anos, com média de 22,7 anos. A Tabela 2 mostra as características da população estudada levando-se em conta dados demográficos, sociais e possíveis fatores de risco para
Tabela 1 - Prevalência do resultado positivo para anti-HIV e anti-HCV entre as puérperas estudadas no período de dezembro de 2001 a maio de $2002 \mathrm{em}$ três maternidades de Cuiabá conveniadas com o SUS.

\begin{tabular}{|c|c|c|c|c|c|}
\hline \multirow[b]{2}{*}{ Hospital } & \multirow{2}{*}{$\begin{array}{c}\text { Total } \\
n^{0}\end{array}$} & \multicolumn{2}{|c|}{ HIV positivo } & \multicolumn{2}{|c|}{ Anti-HCV positivo } \\
\hline & & $\mathrm{n}^{0}$ & $\%$ & $\mathrm{n}^{0}$ & $\overline{\%}$ \\
\hline Geral & 895 & 3 & 0,3 & 6 & 0,7 \\
\hline Santa Helena & 642 & 3 & 0,4 & 0 & 0,0 \\
\hline HUJM & 70 & 2 & 2,9 & 0 & 0,0 \\
\hline Total & 1.607 & 8 & 0,5 & 6 & 0,4 \\
\hline
\end{tabular}

Tabela 2 - Principais características da população de puérperas estudadas quanto à prevalência de HIV e de anti-HCV no período de dezembro de 2001 a maio de 2002 em três maternidades públicas de Cuiabá - MT.

\begin{tabular}{|c|c|c|c|c|c|c|c|}
\hline \multirow[t]{2}{*}{ Variável } & \multirow[t]{2}{*}{ Número* } & \multicolumn{2}{|c|}{$\begin{array}{c}\text { HIV } \\
\text { positivo }\end{array}$} & \multirow[t]{2}{*}{ p-valor } & \multicolumn{2}{|c|}{$\begin{array}{l}\text { Anti-HCV } \\
\text { positivo }\end{array}$} & \multirow[t]{2}{*}{ p-valor } \\
\hline & & $\mathrm{n}^{0}$ & $\%$ & & $\mathrm{n}^{0}$ & $\%$ & \\
\hline Idade (anos) & 80 & 0 & 0,0 & & 0 & 0,0 & \\
\hline 15 a 20 & 575 & 3 & 0,5 & & 0 & 0,0 & \\
\hline 21 a 25 & 525 & 2 & 0,4 & & 2 & 0,4 & \\
\hline 26 a 30 & 267 & 1 & 0,4 & & 0 & 0,0 & \\
\hline 31 a 35 & 111 & 1 & 0,9 & & 3 & 2,7 & \\
\hline$>35$ & 49 & 1 & 2,0 & & 1 & 2,0 & \\
\hline Média $=22,7$ & & & Média $=25,5$ & $0,15^{* * *}$ & & Média $=30,2$ & $<0,001^{* * *}$ \\
\hline \multicolumn{8}{|l|}{ Escolaridade } \\
\hline ensino fundamental & 938 & 7 & 0,7 & 0,15 & 4 & 0,4 & 0,99 \\
\hline ensino médio e superior & 662 & 1 & 0,2 & & 2 & 0,3 & \\
\hline \multicolumn{8}{|l|}{ Atividade profissional } \\
\hline no domicílio & 1.090 & 2 & 0,2 & 0,95 & 4 & 0,4 & 0,71 \\
\hline fora do domicílio & 517 & 6 & 1,2 & & 2 & 0,4 & \\
\hline \multicolumn{8}{|l|}{ Estado civil } \\
\hline solteiras & 354 & 2 & 0,5 & 0,99 & 1 & 0,2 & 0,99 \\
\hline casadas & 372 & 2 & 0,5 & & 2 & 0,5 & \\
\hline amigadas & 794 & 4 & 0,5 & & 3 & 0,4 & \\
\hline separadas & 81 & 0 & 0,0 & & 0 & 0,0 & \\
\hline viúvas & 6 & 0 & 0,0 & & 0 & 0,0 & \\
\hline \multirow{2}{*}{\multicolumn{8}{|c|}{$\begin{array}{l}\text { Tempo de relacionamento } \\
\text { (anos) }\end{array}$}} \\
\hline & & & & & & & \\
\hline$<2$ & 596 & 1 & 0,2 & 0,62 & 1 & 0,2 & 0,42 \\
\hline 2 a 5 & 278 & 2 & 0,7 & & 3 & 1,1 & \\
\hline$>5$ & 291 & 2 & 0,7 & & 1 & 0,3 & \\
\hline \multicolumn{8}{|l|}{ Número de filhos } \\
\hline um & 89 & 1 & 1,1 & 0,11 & 0 & 0,0 & $<0,001$ \\
\hline dois & 645 & 0 & 0,0 & & 0 & 0,0 & \\
\hline três & 460 & 3 & 0,7 & & 10,2 & & \\
\hline quatro & 236 & 3 & 1,3 & & 0 & 0,0 & \\
\hline cinco ou mais & 174 & 1 & 0,6 & & 5 & 2,9 & \\
\hline \multicolumn{8}{|l|}{ Abortamentos prévios } \\
\hline $\operatorname{sim}$ & 306 & 1 & 0,3 & 0,90 & 31,0 & 0,15 & \\
\hline não & 1.301 & 7 & 0,5 & & 30,2 & & \\
\hline \multicolumn{8}{|l|}{ Transfusões prévias } \\
\hline $\operatorname{sim}$ & 78 & 0 & 0,0 & 0,79 & 0 & 0,0 & 0,84 \\
\hline não & 1.529 & 8 & 0,5 & & 6 & 0,4 & \\
\hline \multicolumn{8}{|l|}{ Uso de drogas ilícitas } \\
\hline $\operatorname{sim}$ & 31 & 0 & 0,0 & 0,38 & 0 & 0,0 & 0,91 \\
\hline não & 1.559 & 8 & 0,4 & & 6 & 0,4 & \\
\hline \multicolumn{8}{|l|}{ Tatuagem } \\
\hline $\operatorname{sim}$ & 96 & 0 & 0,0 & 0,76 & 1 & 1,0 & 0,54 \\
\hline não & 1.511 & 8 & 0,5 & & 7 & 0,5 & \\
\hline Total & 1.607 & & 8 & & & 6 & \\
\hline
\end{tabular}

* excluídos os que não responderam

*** p-valor para o teste $t$ de Student 
infecção pelo HIV e HCV. Trinta e uma (1,9\%) mulheres admitiram ter usado drogas ilícitas alguma vez na vida. Destas, duas $(6,4 \%)$ admitiram o uso de cocaína endovenosa e quatro (12,9\%) o uso de crack, o que corresponde respectivamente a $0,1 \%$ e $0,2 \%$ da amostra total. 0 compartilhamento de seringas foi admitido por duas $(0,1 \%)$ mulheres A Tabela 3 mostra a frequiência do uso de preservativos pela população estudada. Observe-se que $22,5 \%$ responderam que nunca fizeram uso de preservativos masculinos em seus relacionamentos. Não foi encontrada associação estatisticamente significante entre uso de preservativos e a infecção pelo HIV ou a presença do anti-HCV. A Tabela 4 mostra dados relacionados ao número de parceiros sexuais e presença de infecção pelo HIV e HCV. Não houve associação significativa entre maior número de parceiros e a infecção pelo HIV ou a presença de anti-HCV. Quando questionadas sobre o comportamento sexual de seus parceiros atuais, 188 $(11,7 \%)$ mulheres responderam que tinham conhecimento de que seu parceiro mantinha intercurso sexual com outras parceiras, $1.088(67,7 \%)$ negavam este fato e $330(20,6 \%)$ tinham dúvidas. Oito $(0,5 \%)$ mulheres afirmaram que tinham conhecimento da situação de comportamento bissexual de seus companheiros. Duas mulheres HIV positivas e uma antiHCV positiva admitiram saber que o parceiro mantinha outros relacionamentos heterossexuais. Oitenta e três $(5,2 \%)$ mulheres relataram história de DST.

Quando questionadas se já tinham feito teste para diagnóstico de infecção pelo HIV, 1.245 (77,4\%) mulheres responderam que sim, $351(21,8 \%)$ responderam que não e $11(0,7 \%)$ não sabiam informar. Das mulheres que responderam sim, 95,8\% (1.193) tinham feito durante o pré-natal da gestação atual. Das 1.607 mulheres do estudo, 13 apresentaram teste anti-HIV positivo pelo método ELISA. 0 resultado foi confirmado por imunofluorescência indireta em oito delas - 0,5\% (IC95\%= $0,2-1,0)$. Seis $(0,4 \% ;$ IC $95 \%=0,1-0,8)$ dentre as 1.607

Tabela 3 - Uso de preservativos masculinos e presença de infecção pelo HIV e HCV em puérperas estudadas no período de dezembro de 2001 a maio de 2002 em três maternidades públicas de Cuiabá-MT.

\begin{tabular}{|c|c|c|c|c|c|}
\hline \multirow[t]{2}{*}{ Uso de preservativos } & \multirow[t]{2}{*}{$\mathrm{n}=1602$} & \multicolumn{2}{|c|}{ HIV positivo* } & \multicolumn{2}{|c|}{ Anti-HCV positivo" ${ }^{* * *}$} \\
\hline & & $\mathrm{n}^{0}$ & $\%$ & $\mathrm{n}^{0}$ & $\%$ \\
\hline Nunca usou & 362 & 2 & 0,5 & 0 & 0,0 \\
\hline Usou algumas vezes & 1.119 & 4 & 0,3 & 5 & 0,4 \\
\hline Usa com frequiência & 110 & 2 & 1,8 & 1 & 0,9 \\
\hline Usa sempre & 11 & 0 & 0,0 & 0 & 0,0 \\
\hline
\end{tabular}

* qui-quadrado $=4,7 ; \mathrm{p}=0,44 * *$ qui-quadrado $=3,0 ; \mathrm{p}=0,70$

Tabela 4 - Número de parceiros na vida e presença de infecção pelo HIV e HCV em puérperas estudadas no período de dezembro de 2001 a maio de 2002 em três maternidades públicas de Cuiabá-MT.

\begin{tabular}{|c|c|c|c|c|c|}
\hline \multirow[t]{2}{*}{ Número de parceiros } & \multirow[t]{2}{*}{$\mathrm{n}=1.542$} & \multicolumn{2}{|c|}{ HIV positivo* } & \multicolumn{2}{|c|}{ Anti-HCV positivo*** } \\
\hline & & $\mathrm{n}^{0}$ & $\%$ & $\mathrm{n}^{0}$ & $\%$ \\
\hline Apenas 1 & 639 & 2 & 0,3 & 0 & 0,0 \\
\hline 2 & 372 & 2 & 0,5 & 3 & 0,8 \\
\hline 3 a 5 & 403 & 4 & 1,0 & 3 & 0,7 \\
\hline 5 a 10 & 117 & 0 & 0,0 & 0 & 0,0 \\
\hline Mais de 10 & 11 & 0 & 0,0 & 0 & 0,0 \\
\hline
\end{tabular}

foram anti-HCV ELISA positivas (Tabela 1). Não havia nenhuma mulher anti-HCV positiva entre as oito mulheres portadoras do HIV.

Das oito mulheres cujos resultados foram positivos para infecção pelo HIV, sete $(87,5 \%)$ referiram que já tinham feito o teste no pré-natal da gestação atual, mas nenhuma tinha conhecimento do resultado. Nenhuma delas já havia realizado teste para anti-HCV.

\section{DISCUSSÃo}

0 aumento do número de casos de infecção pelo HIV associados à categoria de exposição heterossexual, verificado principalmente a partir de 1991, fez-se acompanhar de uma proporção cada vez maior de mulheres infectadas, sendo $72 \%$ destas em idade fértil ${ }^{15}$. Em 2002, 47\% dos casos novos no Brasil ocorreram em mulheres 5 . Esse fenômeno foi acompanhado por um número cada vez maior de crianças infectadas por meio da via de transmissão vertical.

Neste estudo, foram avaliadas 1.607 puérperas internadas em três hospitais de Cuiabá conveniados com o SUS, no período de dezembro de 2001 a maio de 2002. Estes Hospitais apresentam conjuntamente a quase totalidade dos nascimentos pelo SUS na Grande Cuiabá, totalizando 3.767 nascimentos no período estudado. Na mesma época, o número de nascidos vivos em Cuiabá foi de 3.817 crianças (SINASC/SES/MT).

Perdas ocorreram em função de dificuldades operacionais e devido à recusa por parte de algumas pacientes. Nos Hospitais Geral e Santa Helena, o volume de partos é muito grande, com alto fluxo de altas hospitalares todos os dias pela manhã, fazendo com que muitas pacientes deixassem o hospital antes que fosse possível entrevistá-las.

A taxa de prevalência encontrada foi semelhante à taxa nacional divulgada pelo Ministério da Saúde $(0,46 \%)^{5}$, o que reforça a representatividade da amostra obtida. Outros estudos de prevalência apontam valores semelhantes ao valor encontrado no presente estudo, variando de 0,1 a 0,6\% $\%^{1289111^{14}}$. A distribuição de nível de escolaridade e nível sócio-econômico das mulheres pesquisadas foi semelhante a outros estados brasileiros e reitera a hipótese de pauperização da epidemia. No entanto, como o presente estudo só incluiu clientela do Sistema Único de Saúde, não se pode descartar viés de seleção, impedindo conclusão sobre tendência de empobrecimento dos portadores.

$\mathrm{Na}$ amostra estudada, a maioria das mulheres era casada ou vivia maritalmente com seus companheiros, apresentando uniões estáveis e parceiros fixos (72,3\% da amostra geral e $75 \%$ das mulheres soropositivas). Esta situação hoje, ao contrário do que se pensava no início da epidemia, expõe as mulheres à falsa sensação de segurança, uma vez que as mesmas não se percebem em situação de risco. Estudos recentes apontam para o fato de que a grande maioria (68\%) das mulheres infectadas adquiriu 0 vírus de seu parceiro fixo, atual ou anterior ${ }^{12}$.

$\mathrm{Na}$ amostra, não foi encontrada associação entre transfusão de hemoderivados e infecção pelo HIV ou presença 
de anti-HCV. A transmissão dessas infecções através de transfusões de hemoderivados está quase eliminada nos países que adotaram a rotina de screening de doadores de sangue imposta aos bancos de sangue, através de legislação específica, desde 1985 (HIV) e 1993 (HCV). Do mesmo modo, história de DST não teve relação com soropositividade, reforçando a idéia de que as mulheres anti-HIV positivas não pertencem a grupos de risco específicos.

Também, não foi encontrada associação de procedimentos que envolvem risco de transmissão parenteral dos vírus HIV ou HCV como cirurgias prévias, uso de seringas não-descartáveis ou tatuagens. A difusão do uso de seringas e agulhas descartáveis e a adoção de precauções universais reduziram, ou quase eliminaram, o risco de transmissão em procedimentos como acupuntura, tatuagens ou procedimentos odontológicos, constatado em estudo de Assis e cols ${ }^{4}$.

A taxa de uso de preservativos referida no estudo foi muito pequena, pois a maioria $(98,6 \%)$ negou o uso ou referiu uso esporádico. Na amostra estudada não foi possível demonstrar associação desse comportamento com a presença de anticorpos anti-HIV ou anti-HCV. Também, não houve associação estatística entre infecção pelo HIV ou presença do anti-HCV e variáveis que expressam comportamento sexual de risco, como relacionamentos com parceiros que têm múltiplas parceiras ou que têm comportamento bissexual.

0 fato de $74,2 \%$ (1.193) das mulheres informarem que já tinham realizado o teste anti-HIV no pré-natal da gestação atual mostra um significativo aumento da taxa de conscientização dos profissionais de saúde responsáveis pelo atendimento no pré-natal da rede pública. No entanto, somente $5,4 \%$ tinham o resultado impresso em mãos no momento do parto, o que coloca em risco a eficiência do sistema em providenciar o diagnóstico de infecção em tempo hábil para a realização das medidas profiláticas da transmissão vertical, orientando adequadamente as mulheres.

A ausência de associação estatística entre as variáveis classicamente associadas à infecção pelo HIV apresentada nesse estudo pode indicar que a taxa de transmissão heterossexual seja a causa predominante de transmissão para o sexo feminino, tornando mais difícil o reconhecimento da população infectada.

0 número de mulheres HIV-positivas neste estudo foi pequeno, impedindo que se encontrasse associação estatística entre as variáveis estudadas e a soropositividade. Deste modo, não é possível garantir que não tenha ocorrido erro beta em alguma das análises, com perda de sensibilidade do estudo para detectar associações existentes. A despeito destas considerações, os resultados obtidos sugerem que o perfil atual da portadora do HIV foge dos estereótipos de fácil identificação, como no passado. Hoje, a portadora do HIV que procura atendimento pelo SUS é dona de casa, de baixa renda e pouca instrução, que teve poucos parceiros, que leva vida monogâmica e que não teve exposição a fator clássico para o HIV. Uma grande parte dessas mulheres desconhece seu estado sorológico, são assintomáticas, não apresentam alterações no exame clínico, não têm comportamento de risco, e não acreditam que seus parceiros possam ser considerados de risco, ou pelo menos desconhecem tal fato.

Quanto à presença de anticorpos contra o HCV, não foi possível realizar teste confirmatório (immunoblot ou pesquisa do RNA do HCV por PCR). Como o valor preditivo positivo é baixo em situações de baixa prevalência, é lógico considerar que alguns dos testes positivos não seriam confirmados, o que prejudica a análise dos dados apresentados. As associações com idade mais elevada e com maior número de filhos pode ser consequiência do acaso, não sendo permitido maiores conclusões. De qualquer modo, este resultado serve para mostrar que a prevalência do HCV entre puérperas no Mato Grosso deve ser inferior a 5 casos em 1.000.

\section{REFERÊNCIAS BIBLIOGRÁFICAS}

1. Amaral E, Faúndes A, Gonçales NSL, Pellegrino Jr J, Souza CA, Silva JLP. Prevalence of HIV and Treponema pallidum infections in pregnant women in Campinas and their association with socio-demographic factors. São Paulo Medical Journal 114:1108-1116, 1996.

2. Amaro ER, Costa HPF, Darcie S, Kusano E, Richtmann R. Soroprevalência do HIV em sangue de cordão umbilical. Revista Paulista de Pediatria 14: 53-57, 1996.

3. Assis SB. Prevalência de marcadores virais e fatores de risco associados à infecção pelo vírus da hepatite B em escolares de município do norte de Mato Grosso. Dissertação de Mestrado, Universidade Federal do Mato Grosso, Cuiabá, MG, 2000.

4. Assis SB, Valente JG, Fontes CJF, Gaspar AMC, Souto FJD. Prevalência de marcadores do vírus da hepatite $B$ em crianças de 3 a 9 anos em município da Amazônia brasileira. Revista Panamericana de Saúde Pública 15: 2634, 2004.

5. Connor EM, Sperling RS, Gelber R, Kiselev P, Scott G, O'sullivan MJ, Vandyke R, Bey M, Shearer W, Jacobson RL. Reduction of maternal-infant transmission of human immunodeficiency virus type 1 with zidovudine treatment. New England Journal of Medicine 331:1173-1180, 1994.

6. Karon JM, Rosemberg PS, Mcquillan G, Khare M, Gwinn M, Petersen LR. Prevalence of HIV infection in the US: 1984 to 1992. The Journal of the American Medical Association 276:126-131, 1996.

7. Ministério da Saúde. Coordenadoria Nacional de DST/AIDS. Dados epidemiológicos: Brasil, regiões e municípios. Boletim epidemiológico AIDS, ano15: Brasília, p. 18-39, 2002.

8. Neves FRAL, Passos ADC, Gueleri W. Disponibilidade de sorologia anti-HIV como teste voluntário na rotina do atendimento pré-natal em unidades básicas de saúde. Revista de Saúde Pública 33:624-625, 1999.

9. Peixinho ZF, Longo IM, Mendes MC, Mendes NF, Pedrão D, Giraldes RC, Porto AM. Estudo comparativo de soroprevalência de HIV-1 entre o Hospital Guilherme Álvaro (Santos) e outros centros no Brasil e exterior. Revista Brasileira de Alergia e Imunopatologia 1:15-18, 1994.

10. Rakela J, Radkowski M, Tomasz L, Wilkinson J, Adair D, Nowicki M, Kovacs A. Perinatal transmission of HCV from HCV/HIV coinfected mothers to infants: likely role of extrahepatic replication and delayed/absent seroconversion in children. Hepatology 38 (suppl 1): 351A, 2003.

11. Reiche EMV, Morimoto HK, Farias GN, Hisatsugu KR, Séller L, Gomes CLF, Inoue HY, Rodrigues G, Matsuo T. Prevalência de tripanossomíase americana, sífilis, toxoplasmose, rubéola, hepatite $\mathrm{B}$, hepatite $\mathrm{C}$ e da infecção pelo vírus da imunodeficiência humana, avaliada por intermédio de testes sorológicos, em gestantes atendidas no período de 1996 a 1998 no Hospital Universitário Regional Norte do Paraná (Universidade Estadual de Londrina, Paraná, Brasil). Revista da Sociedade Brasileira de Medicina Tropical 33: 519-527, 2000.

12. Santos N. Mulheres HIV positivas, reprodução e sexualidade. Revista de Saúde Pública 36 (supl 4):12-23, 2002. 
13. Sczwarcwald CL, Castilho EA. Estimativa do número de pessoas de 15 a 49 anos infectadas pelo HIV, Brasil, 2000. Brasil, Ministério da Saúde, Coordenação Nacional de DST/AIDS. Disponível em < http:// www.aids.gov.br> Acesso em 02/03/2002, 1999.

14. Souza ES, Figueira FS, Silva GA, Vilarim JA, Souza AI, Pessoa VP. Soroprevalência da infecção pelo HIV-1 em gestantes atendidas no IMIP, Recife- Brasil. Revista do IMIP 1: 925-929, 1995.
15. Terrault NA, Busch M, Murphy E, Tong M, Dvorkin J, Alter MJ. Sexual transmission of hepatitis $\mathrm{C}$ vírus in heterosexual monogamous couples the HCV partners study. Hepatology 38 (suppl 1): 183A, 2003.

16. Valente JG. New exclusion criteria for blood donor deferral at State Institute of Hematology, Rio de Janeiro city, Brasil: a case control study for the transmission of the human immunodeficiency virus. (PhD Thesis). School of Hygiene and Public Heath. Johns Hopkinns University. Baltimore, 1995. 